REPeC, Brasília, v. 9, n. 4, art. 1, p. 362-379, out./dez. 2015

Disponível online em www.repec.org.br

D0l: http://dx.doi.org/10.17524/repec.v9i4.1289

\title{
Estrutura de Propriedade e Disclosure Econômico e Socioambiental nas Maiores Empresas do Brasil
}

\section{Resumo}

A evidenciação das práticas sustentáveis tornou-se importante na busca por vantagens competitivas, possibilitando o atendimento às expectativas dos diversos stakeholders. Assim, o estudo tem por objetivo investigar a relação entre a estrutura de propriedade e o disclosure voluntário econômico e socioambiental nas maiores empresas brasileiras, analisando a concentração acionária e a identidade do acionista controlador. Para a análise, foram consideradas as perspectivas econômica, social e ambiental abordadas tanto de forma individual quanto conjunta. A amostra reúne 47 empresas das 100 maiores companhias abertas listadas na BM\&FBOVESPA, conforme a revista Exame Melhores e Maiores, edição 2013. A pesquisa possui caráter descritivo e abordagem quantitativa dos dados, empregando a Regressão Linear Múltipla como método estatístico. A análise descritiva das perspectivas do disclosure (econômico, social, ambiental e sustentabilidade) evidenciou que o aspecto ambiental apresentou menor média de divulgação. As organizações de controle estatal destacaram-se com maior média em três dos quatro níveis de disclosure: econômico, social e de sustentabilidade. Quanto à aplicação do teste estatístico, os modelos de regressão não apresentaram significância estatística, indicando que, para as empresas da amostra, a estrutura de propriedade não exerce influência sobre o disclosure econômico e socioambiental.

Palavras-chaves: Estrutura de propriedade e controle; Evidenciação; Divulgação; Sustentabilidade; Responsabilidade Social Corporativa (RSC).

\section{Tatiana Aquino Almeida}

Bacharel em Ciências Contábeis pela Universidade Federal do Ceará (UFC) e mestranda em Administração e Controladoria pela UFC. Contato: Av. da Universidade, 2431, Benfica, Fortaleza-CE, CEP: $60.020-180$.

E-mail: tatianaaquino.ufc@gmail.com

Lahis Muriel Feliciano dos Santos Bacharel em Ciências Contábeis pela Universidade Federal do Ceará (UFC) e mestranda em Administração e Controladoria pela UFC. Contato: Av. da Universidade, 2431, Benfica, Fortaleza-CE, CEP: $60.020-180$.

E-mail: lahismuriel@gmail.com

Augusto Cézar de Aquino Cabral Doutor em Administração pela Universidade Federal de Minas Gerais (UFMG) e professora da Universidade Federal do Ceará (UFC). Contato: Av. da Universidade, 2431, Benfica, Fortaleza-CE, CEP: $60.020-180$.

E-mail: cabral@ufc.br

\section{Sandra Maria dos Santos} Doutora em Economia pela Universidade Federal de Pernambuco (UFPE) e professora da Universidade Federal do Ceará (UFC). Contato: Av. da Universidade, 2431, Benfica, Fortaleza-CE, CEP: 60.020-180. E-mail: smsantos@ufc.br

Maria Naiula Monteiro Pessoa Doutora em Engenharia de Produção pela Universidade Federal de Santa Catarina (UFSC) e Professora da Universidade Federal do Ceará (UFC). Contato: Av. da Universidade, 2431, Benfica, Fortaleza-CE, CEP: $60.020-180$.

E-mail: naiula@ufc.br 


\section{Introdução}

A estrutura de propriedade define-se como a forma na qual se distribui o capital de uma empresa, tanto em relação aos votos quanto em relação ao grau de concentração do capital (Sonza, 2012). Neste sentido, percebe-se que a natureza da propriedade e a identidade dos acionistas controladores exercem influência sobre o desempenho da empresa, devido à dependência dos posicionamentos estratégicos em relação ao alinhamento de interesses entre essas partes (Braga, Santos, Silva \& Nunes, 2011). Tem-se, então, como abordagens da estrutura de propriedade: (i) a concentração acionária e (ii) a identidade do acionista controlador, sendo que esta última pode ser categorizada, de acordo com Carvalhal-da-Silva (2004), em indivíduos ou famílias, investidores estrangeiros, governo e investidores institucionais.

Verificada a influência dos acionistas controladores sobre a empresa, Díez, Gago e García (2011) destacam que o grau de envolvimento em práticas relacionadas à sustentabilidade pode apresentar diferenciações, conforme a estrutura de propriedade da empresa, ou, mais especificamente, de acordo com a concentração da propriedade. Ghazali (2007) corrobora ao destacar que a estrutura de propriedade é um dos determinantes da divulgação de informações acerca da sustentabilidade das empresas. Destarte, insere-se o conceito de sustentabilidade empresarial, que é caracterizado por englobar os aspectos econômicos, sociais e ambientais na determinação da atuação empresarial (Gallo \& Christensen, 2011).

Considerando-se que a evidenciação de informações socioambientais pode gerar valor para as empresas (Borges, Rosa \& Ensslin, 2010) e legitimar a sua atuação perante a sociedade (Cardoso, De Luca \& Almeida, 2012; Sampaio, Gomes, Bruni \& Dias, 2012; Costa, Torres, Vasconcelos \& De Luca, 2013; Muttakin \& Subramaniam, 2015), tem-se a teoria da Legitimidade como base do presente estudo. Assim, conforme Deegan (2005), a referida teoria sugere que as organizações devem se adequar às expectativas da sociedade e demais stakeholders para que possam manter a sua continuidade.

Crisóstomo, Freire e Parente (2013) destacam que proprietários e gestores têm se preocupado com questões relativas à sustentabilidade, visto que, entre outros motivos, tais questões contribuem na busca pela legitimidade empresarial. Ao exercerem influência na atuação de uma empresa, visando ao sucesso empresarial, os proprietários têm a capacidade de influenciar as decisões referentes à atuação econômica, social e ambiental e a sua respectiva divulgação, aspectos estes, primordiais para o alcance da legitimidade.

Diante do exposto e considerando-se a influência da estrutura de propriedade nas decisões sobre divulgação voluntária de sustentabilidade nas organizações a partir dos preceitos da teoria da Legitimidade, o presente estudo sugere a seguinte questão de pesquisa: Qual a relação entre a estrutura de propriedade e o disclosure econômico e socioambiental nas maiores empresas brasileiras?

O objetivo geral deste estudo consiste em investigar a relação entre a estrutura de propriedade e o disclosure voluntário econômico e socioambiental nas maiores empresas brasileiras. Para isso, estabeleceram-se dois objetivos específicos, a saber: (i) identificar a relação entre o controle acionário e o disclosure voluntário econômico e socioambiental nas maiores empresas brasileiras; (ii) verificar a relação entre a identidade do acionista controlador e o disclosure voluntário econômico e socioambiental nas maiores empresas brasileiras.

Em concordância com a problemática e com os objetivos de pesquisa, o presente estudo propõe as seguintes hipóteses: $\mathrm{H}_{1}$ : $\mathrm{O}$ controle acionário está relacionado com o disclosure econômico e socioambiental; $\mathrm{H}_{2}$ : A identidade do acionista controlador está relacionada com o nível de disclosure econômico e socioambiental.

No Brasil, diversos são os estudos que analisam a estrutura de capital (Dami, Rogers \& Ribeiro, 2007), ou o nível de divulgação de informações voluntárias (Braga, Oliviera \& Salotti, 2009), ou, ainda, relacionam os dois em algum contexto específico (Silva, Chan, Furuta \& Martins, 2007; Braga et al., 2011; Iyer \& Lulseged, 2013). No entanto, poucos são os que investigam a associação entre eles em um contexto mais amplo. Assim, esta pesquisa diferencia-se ao buscar verificar a relação da estrutura de propriedade, especificamente o controle acionário e a identidade do acionista controlador com o nível de disclosure nas esferas econômica, social e ambiental. 
A presente pesquisa caracteriza-se como descritiva, com abordagem quantitativa e documental. A amostra final é composta por 47 empresas listadas na Bolsa de Valores de São Paulo (BM\&FBOVESPA), conforme o ranking da Revista Exame Melhores e Maiores, edição 2013. Os dados foram coletados a partir da análise de conteúdo dos Relatórios de Sustentabilidade de 2012 das empresas que compuseram a amostra e de informações disponibilizadas no Formulário de Referência, divulgado no site da BM\&FBOVESPA. Quanto ao tratamento dos dados, foi utilizada a análise descritiva, com o objetivo de caracterizar a amostra e, para a análise estatística, foi empregada a Regressão Linear Múltipla.

Além desta introdução, a pesquisa foi dividida em mais quatro seções. Na segunda seção é apresentada a base teórica na qual o trabalho está fundamentado, abordando aspectos relativos à estrutura de propriedade e ao disclosure econômico e socioambiental e relacionando ambos os aspectos na legitimação da atuação empresarial perante a sociedade. A terceira seção trata da abordagem metodológica utilizada para a consecução dos objetivos da pesquisa. Na quarta seção, são apresentados e discutidos os resultados obtidos a partir do emprego dos aspectos metodológicos expostos na seção 3. Por fim, a quinta seção apresenta as considerações finais do estudo.

\section{Referencial Teórico}

\subsection{Estrutura de propriedade e controle}

O crescimento das organizações e a complexidade resultante desse processo levaram à separação da propriedade e do controle, sendo que esse processo de transição da propriedade foi previsto nos estudos de Berle e Means (1932). Essa separação é então verificada, prioritariamente, a partir da existência de dois tipos de ações nas empresas de capital aberto: as preferenciais e as ordinárias.

As ações preferenciais caracterizam a propriedade da organização e são as que fornecem o direito sobre fluxo de caixa, no entanto, não apresentam o direito de voto. Já as ações ordinárias caracterizam o controle da organização, visto que elas fornecem o direito de voto (Okimura, Silveira \& Rocha, 2007; Sarlo, 2009). Assim, ressalta-se que a concentração de capital possui papel de destaque, uma vez que é por meio da posse de ações ordinárias que o acionista irá participar das decisões da empresa.

Diversas pesquisas mostram que, no Brasil, a separação entre controle e direito sobre fluxo de caixa é marcada pelo fato de as empresas emitirem ações preferenciais (Carvalhal-da-Silva, 2004), identificando-se, ainda, uma alta concentração de propriedade na composição acionária das empresas, além de apresentarem modelo familiar (Brandão, 2004; Sarlo, 2009; Braga et. al., 2011). Apesar disso, Dami et al. (2007) destacam a concentração de propriedade como uma forma de os proprietários monitorarem a gerência.

Neste sentido, a identidade do acionista controlador é vista como de grande relevância no direcionamento das ações empresariais, visto que, de acordo com Okimura et al. (2007), supõe-se que a estrutura de propriedade influenciará o desempenho da empresa. Assim, percebe-se a influência não somente da quantidade de capital que o acionista possui como também da identidade do referido acionista; ou se é uma família, pessoa particular, trabalhador, gestor, instituição financeira ou empresa estrangeira (Javid \& Iqbal, 2008).

Na literatura, diversas são as classificações dadas para as identidades dos acionistas, dentre elas ressaltam-se as realizadas por Okimura et al. (2007) e por Carvalhal-da-Silva (2004). O primeiro segrega a classificação das identidades dos controladores em: propriedade privada estrangeira; propriedade privada nacional; propriedade familiar ou pessoal, propriedade por bancos/instituições financeiras; e propriedades por fundo de pensão. Já o segundo classifica em: indivíduos ou famílias; investidores estrangeiros; governo; e investidores institucionais. A classificação de Carvalhal-da-Silva (2004) é a adotada pelo presente estudo, visto que o autor abrange as diversas identidades acionárias de forma clara, objetiva e concisa.

Além disso, Braga et. al (2011) - afirmam que o controle acionário impacta na comunicação da empresa com os usuários externos, principalmente na divulgação voluntária, já que não há normas preesta- 
belecidas. Deste modo, verifica-se que o modelo de gestão e as políticas empregadas pela organização, nas quais se incluem as políticas acerca da divulgação, podem ser determinados tanto pelo controle acionário quanto pela identidade do acionista controlador.

Neste contexto, Gondrige, Espejo, Clemente e Silva (2011) apontam que a divulgação voluntária varia bastante entre as empresas. No entanto, esse tipo de divulgação tem ganhado um maior foco devido a questões relacionadas à internacionalização das entidades e crises financeiras que ocorreram nos últimos anos. Assim, a necessidade de se considerarem os interesses dos principais grupos relacionados à atividade empresarial (Díez et al., 2011) e o aumento da relevância e do interesse da sociedade por uma atuação social (Borba, 2006) e ambientalmente (Borges et al., 2010) responsável, em conjunto com a noção de que tais atuações podem impactar no desempenho empresarial (Saleh, Zulkifli \& Muhamad, 2010), contribuiu para que as organizações adotem uma postura diferenciada quanto à sua divulgação, que é caracterizada em diversos países como voluntária.

\subsection{Disclosure econômico e socioambiental e a Teoria da Legitimidade}

As empresas são responsáveis pela transformação dos recursos naturais em produtos e serviços fornecidos à sociedade, destacando-se como um dos principais agentes no processo de desenvolvimento econômico (Braga et. al, 2009). No entanto, os processos históricos apontam que o comportamento empresarial muda a partir do intenso apoio dos seus stakeholders (Amran \& Ooi, 2014), posto que, gradativamente, surgiu a necessidade da conciliação do desenvolvimento econômico com a preservação do meio ambiente (Roque \& Cortez, 2006).

As questões que envolvem a responsabilidade socioambiental das organizações passaram por mudanças significativas nas últimas décadas do século XX (Fonseca, Almeida \& França, 2012). Isso é verificado por Borba (2006), ao destacar que as crescentes desigualdades sociais provocaram, principalmente a partir da década de 70, questionamentos e reivindicações acerca do papel da empresa perante a sociedade. Nesta mesma perspectiva, Ribeiro, Van Bellen e Carvalho (2011) afirmam que a sociedade passa a se preocupar com a degradação ambiental na medida em que os problemas advindos dela ganham proporções graves, assim, as pressões sociais atuam como uma forma de exigir a adoção de práticas ambientalmente adequadas.

Sob uma perspectiva mais ampla, a continuidade das organizações encontra-se atrelada ao atendimento das "necessidades de todos os agentes envolvidos: clientes, governos, comunidade, funcionários e acionistas" (Borges et al., 2010, p. 404), que, consequentemente, apresentam diferentes demandas quanto às questões relacionadas à sustentabilidade empresarial.

Verifica-se, portanto, que as empresas não devem possuir uma conduta que se restrinja apenas à obtenção do lucro, visto que os aspectos socioambientais também devem ser levados em consideração na atuação empresarial (Borba, 2006; Ghazali, 2007; Braga et. al, 2009; Díez et al., 2011; Cardoso et al., 2012). Assim, o conceito da sustentabilidade empresarial abrange, de modo individual e integrado, as dimensões econômica, social e ambiental na determinação da atuação das empresas (Gallo \& Christensen, 2011). Vale ressaltar que o conceito supracitado assemelha-se ao de Responsabilidade Social Corporativa (RSC), tendo em vista que Iyer e Lulseged (2013) destacam que a RSC refere-se à contribuição voluntária da empresa para o desenvolvimento sustentável, além daquilo que é exigido por leis ou regulamentos.

Tendo em vista a influência das práticas socioambientais e da sua respectiva divulgação na legitimação da empresa frente à sociedade, emerge o arcabouço teórico referente à teoria da Legitimidade no qual se baseia o presente estudo. Nesse sentido, Deegan (2005) destaca que a legitimidade de uma organização depende das práticas de negócio empregadas em uma sociedade, as quais devem ser adequadas ao contexto no qual a empresa está inserida. Além disso, conforme apontado pelo autor, a teoria da Legitimidade preceitua que as organizações devem atender e se adequar às expectativas da sociedade, caso contrário a entidade enfrentará diversos obstáculos, como, por exemplo, a dificuldade em atrair capital e clientes. 
A referida teoria está baseada no constructo de que "existe uma espécie de 'contrato social' entre as organizações e a sociedade em que atuam, representando um conjunto de expectativas implícitas ou explícitas de seus membros a respeito da forma como elas devem operar" (Dias, 2007, p. 6). Beuren e Söthe (2009) complementam ao afirmar que a empresa precisa demonstrar continuamente a sua importância à sociedade, buscando a legitimação dos seus atos. As empresas buscam, portanto, realizar esforços para serem percebidas como responsáveis (Costa et al., 2013).

Sampaio et al. (2012) afirma que também são exercidas pressões no que diz respeito à divulgação das informações referentes à atuação no âmbito da sustentabilidade, funcionando como um instrumento de legitimação. Os autores destacam um crescimento no nível de evidenciação desses tipos de informações, refletindo a preocupação das organizações no tocante à percepção da sociedade quanto a esses aspectos. Martini, Silva e Mattos (2014) corroboram ao afirmar que, cada vez mais, as empresas monitoram, quantificam e divulgam informações relativas à sustentabilidade empresarial para as partes interessadas.

De acordo com Murcia (2009), algumas empresas divulgam informações que vão além daquelas exigidas por lei, o chamado disclosure voluntário. Para o autor, essa forma de divulgação complementa o disclosure obrigatório, tendo em vista o fornecimento de informações adicionais sobre as operações da empresa, o que gera maiores vantagens para os investidores. Tais investidores possuirão informações mais detalhadas a respeito da organização, as quais poderão influenciar o processo de tomada de decisão.

Considerando-se as pressões por uma atuação empresarial sustentável, a divulgação de informações torna-se necessária para o suprimento dessa demanda informacional. Os relatórios não financeiros demonstram, entre outros aspectos, transparência aos stakeholders, sendo o relatório de sustentabilidade fundamental na efetiva comunicação às partes interessadas (Amran \& Ooi, 2014). Costa et al. (2013) corroboram ao afirmar que, para a legitimação das práticas de responsabilidade social e ambiental adotadas, é imprescindível a publicação de informações por meios eficazes e de boa qualidade.

Apesar de a divulgação desse tipo de informação não ser obrigatória em diversos países, dentre os quais se inclui o Brasil, Garcia, Cintra, Ribeiro e Dibbern (2015), ressaltam que, de forma semelhante aos relatos financeiros, os relatórios de sustentabilidade devem fornecer informações de qualidade aos stakeholders. O relatório de sustentabilidade destaca-se como o principal meio pelo qual as organizações realizam essa divulgação, sendo o modelo da Global Reporting Iniciative (GRI) o principal canal utilizado para a realização dessa divulgação. Neste sentido, Sampaio et al. (2012) destacam que a adoção das diretrizes da GRI traz certos benefícios à organização, como a evidenciação de iniciativas voluntárias e o comprometimento com o desenvolvimento sustentável.

Diversos pesquisadores apontam uma série de motivações para que as empresas divulguem informações econômicas e socioambientais de forma voluntária. Podem-se citar: a antecipação das empresas frente a potenciais regulamentações governamentais e a redução de custos relativos às regulamentações (Iyer \& Lulseged, 2013); o objetivo de garantir benefícios econômicos advindos dessa divulgação (De Luca, Assunção \& Costa, 2013); a possibilidade de geração de valor para as empresas (Borges et al., 2010); e a legitimação de sua atuação perante a sociedade (Sampaio et al., 2012). Assim, vários podem ser os fatores que influenciam a divulgação de informações referentes à sustentabilidade empresarial, como a rentabilidade (Ghazali, 2007; Murcia, 2009; De Luca et al., 2013; Iyer \& Lulseged, 2013; Muttakin \& Subramaniam, 2015); o tamanho da organização (Ghazali, 2007; Braga et. al., 2009; Murcia, 2009; Iyer \& Lulseged, 2013; Muttakin \& Subramaniam, 2015), o endividamento (Murcia, 2009; Braga et. al., 2009 ) e o controle acionário (Ghazali, 2007; Braga et. al., 2009; Murcia, 2009).

Na medida em que o processo de evidenciação é impactado pelo controle acionário, destaca-se que a estrutura de propriedade é um dos determinantes da divulgação de informações acerca da sustentabilidade das empresas (Ghazali, 2007). Crisóstomo et al. (2013) destacam que os proprietários e os gestores têm se preocupado com as questões relativas à sustentabilidade, visto que esta passou a ser considerada uma forma de melhorar a imagem e a reputação da organização, além de contribuir na busca pela legitimidade empresarial. Os autores afirmam, ainda, que tanto os acionistas proprietários quanto os controladores podem influenciar as políticas referentes às questões relativas à sustentabilidade da empresa. 


\subsection{Estrutura de propriedade e o disclosure econômico e socioambiental}

Wahab, How e Verhoeven (2008) apontam que a divulgação social corporativa é um reflexo da prestação de contas e da transparência de uma organização. Os autores ressaltam o fato de os investidores institucionais mostrarem-se sensíveis às práticas de divulgação de informações, desde que elas influenciem no potencial para oportunidades de negócios rentáveis. Pressupõe-se, portanto, que a divulgação de informações é um meio de legitimar a sua atuação perante o mercado e a sociedade (Ghazali, 2007; Sampaio et al., 2012). Assim, pode-se afirmar que a estrutura de propriedade influencia as escolhas das políticas da empresa, em especial os aspectos relacionados à divulgação voluntária de informações acerca da sustentabilidade empresarial.

Crisóstomo et al. (2013) afirmam ser viável considerar que a propriedade também pode influenciar a política de sustentabilidade. Além disso, Dam e Scholtens (2013) constataram essa relação entre controle acionário e políticas de divulgação, enfatizando que quanto maior a concentração acionária, menor o nível de divulgação. Já Crisóstomo et al. (2013), ao sugerirem uma relação entre a estrutura de propriedade e a Responsabilidade Social Corporativa (RSC), analisaram 64 empresas brasileiras de capital aberto, no período 1997-2008, e verificaram que a RSC é positivamente influenciada pela concentração de propriedade no Brasil. Segundo esses autores, tal resultado pode ser um indicativo de que os grandes acionistas das empresas brasileiras consideram a RSC uma forma importante de melhorar a imagem e a reputação, bem como incentivar a realização de projetos de RSC e sua divulgação.

Nesse contexto, propõe-se a seguinte hipótese:

$\mathbf{H}_{1}$ : O controle acionário está relacionado com o disclosure econômico e socioambiental.

García, Navarro e Ansón (2014) destacam que, no âmbito da Responsabilidade Social Corporativa das empresas, torna-se necessário considerar não apenas a concentração dos grandes acionistas, mas também da sua identidade. Corroborando os autores, Oh, Chang e Martynov (2011) afirmam que os proprietários impactam diferentemente nas ações de sustentabilidade empresariais. Nessa perspectiva, tem-se que a identidade do acionista pode influenciar a Responsabilidade Social Corporativa (Oh et al., 2011; Dam \& Scholtens, 2012; Block \& Wagner, 2014) e, portanto, a divulgação de informações sobre sustentabilidade (Ghazali, 2007; Saleh et al., 2010; Iyer \& Lulseged, 2013).

Dyer e Whetten (2006) apontam que uma das motivações para a realização de práticas socialmente responsáveis consiste na influência que a reputação da empresa exerce sobre a da própria família, visto que o nome familiar está diretamente ligado ao da empresa. Deste modo, na perspectiva das empresas familiares, esse tipo de divulgação auxilia na proteção dos negócios e na reputação da família (Iyer \& Lulseged, 2013). Entretanto, García et al. (2014) enfatizam que, apesar de a natureza familiar de uma empresa aparentar influenciar a implementação de ações voltadas para a responsabilidade social empresarial, não há resultados empíricos conclusivos quanto ao sinal de tal relacionamento.

Tal inconclusividade é verificada em estudos como os realizados por Block e Wagner (2014) e Iyer e Lulseged (2013). Assim, baseados na perspectiva da identidade familiar e organizacional, Block e Wagner (2014) buscaram analisar se o efeito da propriedade familiar pode diferir nas diversas dimensões da Responsabilidade Social Corporativa (RSC). Dessa forma, os resultados encontrados pelos autores mostraram que a propriedade familiar está negativamente associada à performance de RSC relacionada com a comunidade e positivamente associada com variedade, empregado, ambiente e aspectos relacionados ao produto da RSC. Já no contexto do disclosure da RSC, Iyer e Lulseged (2013) realizaram pesquisa que objetivou investigar a associação entre empresas familiares e a divulgação da Responsabilidade Social Corporativa por meio dos relatórios de sustentabilidade de grandes empresas norte-americanas pertencentes ao S\&P 500. Os autores não encontraram diferença estatisticamente significante entre as empresas familiares e não familiares da amostra quanto à divulgação de informações nos relatórios de sustentabilidade. 
Organizações que são propriedade do governo são mais sensíveis politicamente, sendo que isso ocorre devido a uma maior percepção das atividades dessas empresas pelo público em geral, visto que a posse de tais companhias pelo governo indica que, indiretamente, a sua propriedade também é pública (Ghazali, 2007). Muttakin e Subramaniam (2015) argumentam que as atividades voltadas para a responsabilidade social podem refletir a forma na qual as entidades governamentais estão propensas a atender tanto aos interesses empresariais quanto ao bem-estar da sociedade.

Neste sentido, Ghazali (2007) aponta que, para legitimar a sua atuação, tais empresas tendem a possuir um maior envolvimento com atividades socialmente responsáveis, bem como uma maior divulgação de tais informações. O referido autor examinou a influência da estrutura de capital na divulgação sobre Responsabilidade Social Corporativa (RSC) nos relatórios anuais de empresas da Malásia e constatou, como um dos resultados obtidos na pesquisa, que empresas que possuem grandes parcelas da propriedade em poder do governo divulgam mais informações relacionadas à RSC nos relatórios anuais.

A origem do controle acionário estrangeiro é outro fator influenciador do nível de disclosure econômico e socioambiental das organizações. Para Muttakin e Subramaniam (2015), os proprietários estrangeiros são suscetíveis a serem mais conscientes e sensíveis às expectativas crescentes de uma atuação socialmente responsável por parte das empresas, impactando na divulgação de tal atuação. Braga et al. (2009) - argumentam que, além dos aspectos de ordem cultural, acredita-se que o custo de divulgação de informações de empresas que possuem controle acionário estrangeiro é relativamente menor do que empresas sob controle acionário brasileiro. Assim, os autores apontam que tais organizações estariam propensas a divulgar mais informações ambientais do que as empresas de controle acionário nacional.

Tal relacionamento foi abordado por Braga et al. (2011) - , que analisaram a influência da origem do controle acionário no nível de disclosure ambiental das empresas do setor de energia elétrica do Brasil, a partir do exame de uma amostra de 60 companhias no período de 2006 a 2009. Em suma, os resultados encontrados pelos autores apontaram que empresas de controle acionário estrangeiro apresentaram um nível médio de divulgação ambiental ligeiramente superior ao das empresas de controle acionário brasileiro.

A identidade institucional também é apontada como influenciadora da divulgação de informações relativas à sustentabilidade empresarial. Saleh et al. (2010), ao explorar em a relação entre o disclosure de RSC e a propriedade institucional de empresas listadas publicamente na Malásia, analisaram uma amostra que abrange 200 grandes empresas da Malásia, no período de 2000 a 2005. Como resultados, os testes estatísticos confirmaram a existência de relação significante e positiva entre o nível de divulgação de informações da RSC com os investidores institucionais. Assim, os autores concluíram que ao se engajarem mais em ações sustentáveis, as empresas atraem mais investidores, além de melhorar a reputação e a imagem da organização.

Além disso, os investidores institucionais caracterizam-se por possuírem mais recursos e melhores condições de organização, propiciando um maior potencial de ativismo na governança corporativa (Brandão, 2004). Corroborando a assertiva, Gillan e Starks (2003) destacam a influência direta desses investidores sobre as atividades administrativas. Lima (2013) enfatiza que as diversas iniciativas as quais buscaram instituir práticas de governança corporativa no Brasil, em conjunto com o ativismo dos investidores institucionais, tinham como um de seus objetivos o aumento da qualidade da informação fornecida pelas organizações.

Diante do exposto, propõe-se a seguinte hipótese:

$\mathbf{H}_{2}$ : A identidade do acionista controlador está relacionada com o nível de disclosure econômico e socioambiental.

Diante do exposto, notam-se diversos tipos de análise, considerando a relação entre estrutura de propriedade e Responsabilidade Social Corporativa (RSC). No entanto, as análises focam características específicas da propriedade ou alguma dimensão da RSC. Assim, o presente estudo diferencia-se ao contemplar, no contexto societário brasileiro, as duas características principais da estrutura de propriedade - identidade e controle - além de explorar todas as perspectivas - econômica, social e ambiental - individualmente e em conjunto. 


\section{Metodologia}

A presente pesquisa caracteriza-se como descritiva quanto aos objetivos, visto que busca identificar e obter informações sobre a relação existente entre a estrutura de propriedade e o disclosure de informações econômica e socioambientais (Collis \& Hussey, 2005). Quanto à natureza, destaca-se como quantitativa, pois analisa dados numéricos por meio de testes estatísticos. Verifica-se que a pesquisa possui caráter documental devido à utilização de dados secundários referentes ao exercício social de 2012, obtidos através do website da BM\&FBOVESPA e dos Relatórios de Sustentabilidade divulgados nos moldes da GRI versão G3.1, disponíveis nos websites das empresas.

A população da pesquisa compreende as 100 maiores companhias de capital aberto, conforme ranking da Revista Exame Melhores e Maiores, edição 2013. Para selecionar a amostra, foram utilizados os seguintes critérios: (i) possuir Relatório de Sustentabilidade no modelo GRI, que apresente o Índice Remissivo; (ii) apresentar acionista controlador; e (iii) disponibilizar todas as informações financeiras necessárias para a análise.

A partir da aplicação desses critérios, ocorreram as seguintes exclusões: (i) 40 empresas, sendo 35 devido à não divulgação de Relatório de Sustentabilidade nos moldes da GRI e cinco devido à ausência de Índice Remissivo GRI no relatório; (ii) sete empresas; e (iii) cinco empresas, sendo que estas se referiam aos bancos, visto que estes não apresentavam todas as informações financeiras necessárias para o cálculo das variáveis devido à estrutura patrimonial diferenciada. Além disso, houve a exclusão de uma empresa que não realizou a divulgação do Formulário de Referência, impossibilitando a coleta dos dados. Assim, a partir das exclusões realizadas, a amostra final do estudo totalizou 47 empresas.

A análise do nível de disclosure foi realizada em três perspectivas, individualmente - econômica, social e ambiental -, bem como das três de forma integrada. Esta última é denominada de disclosure de sustentabilidade ou disclosure econômico e socioambiental, visto que é considerado o disclosure total das três categorias. A referida análise foi realizada a partir das informações evidenciadas nos Relatórios de Sustentabilidade GRI. O modelo GRI G3.1 apresenta um total de 84 indicadores, segregados em três dimensões: econômica (9), ambiental (30) e social (45).

A mensuração do nível de disclosure dessas informações foi realizada por meio da análise de conteúdo, definida por Hair, Babin, Money e Samouel (2005) como uma técnica de obtenção de dados por meio da análise sistemática e da observação, em que são identificados o conteúdo e as características de informações presentes no texto. Tal análise baseia-se nos indicadores declarados no Índice Remissivo dos Relatórios de Sustentabilidade elaborados nos moldes da GRI. Assim, para cada indicador, utilizou-se a seguinte codificação: 0 (zero), caso o item não seja divulgado pela empresa; 0,5 (zero vírgula cinco), para divulgação parcial; e 1 (um), para divulgação total do item. O nível de disclosure, em cada uma das perspectivas, foi calculado a partir da razão entre o somatório da pontuação referente aos indicadores divulgados por empresa e o total de indicadores da perspectiva.

Quanto ao controle acionário, a mensuração foi feita por meio do percentual de ações ordinárias do primeiro acionista controlador da organização. No que diz respeito à identidade de tal acionista, foi realizado o rastreio do acionista controlador, com o objetivo de descobrir a identidade do proprietário de cada empresa. Deste modo, com base na categorização realizada por Carvalhal-da-Silva (2004), foi empregada a seguinte classificação: estatal (Governo: município, estado ou União), estrangeira (investidores estrangeiros, sendo tanto indivíduos quanto instituições), familiar (indivíduos ou famílias) e institucional (bancos, companhias de seguros, fundos de pensão ou de investimentos). A identidade acionária é, portanto, uma variável dummy.

Inicialmente, foi realizada a análise descritiva dos dados, com o objetivo de detalhar as variáveis estudadas: nível de disclosure e o seu relacionamento com a estrutura de propriedade (controle e identidade). Para que a análise do nível de evidenciação com base no controle acionário pudesse ser operacionalizada, realizou-se a segregação das empresas em três grupos, que foram definidos por Pedersen e Thomsen (1997) a partir do percentual de ações detido pelo acionista controlador: (i) menos de $20 \%$ do controle, 
(ii) entre $20 \%$ e 50\%; e (iii) mais de 50\% do controle. Destaca-se que tal classificação foi realizada apenas para fins de análise descritiva, com o objetivo de melhor apresentar e caracterizar a amostra do estudo.

Para investigar a relação entre a estrutura de propriedade e o disclosure econômico e socioambiental, aplicou-se a técnica estatística de Regressão Linear Múltipla. Segundo Cunha e Coelho (2007), a regressão tem como objetivo estabelecer uma relação funcional entre duas ou mais variáveis envolvidas, com o intuito de descrever um fenômeno.

Dessa forma, o Tabela 1 apresenta as variáveis dependentes, independentes e de controle utilizadas na Regressão Linear Múltipla.

Tabela 1

\section{Variáveis utilizadas no modelo de regressão}

\begin{tabular}{|c|c|c|c|c|c|}
\hline Variável & & Métrica & Operacionalização & Fonte de coleta & Base teórica \\
\hline \multirow{4}{*}{ Dependente } & $\begin{array}{l}\mathrm{DISC}_{-} \\
\mathrm{ECO}\end{array}$ & $\begin{array}{l}\text { Disclosure } \\
\text { Econômico }\end{array}$ & \multirow{4}{*}{$\begin{array}{c}\text { Número de } \\
\text { indicadores } \\
\text { divulgados/Número } \\
\text { total de indicadores }\end{array}$} & \multirow{4}{*}{$\begin{array}{l}\text { Relatório de } \\
\text { Sustentabilidade } \\
\text { - modelo GRI }\end{array}$} & \multirow{4}{*}{$\begin{array}{l}\text { Murcia (2009); De Luca et al. } \\
\text { (2013) }\end{array}$} \\
\hline & $\begin{array}{l}\text { DISC_ } \\
\text { SOC }\end{array}$ & Disclosure Social & & & \\
\hline & $\begin{array}{l}\text { DISC } \\
\text { AMB }\end{array}$ & $\begin{array}{l}\text { Disclosure } \\
\text { Ambiental }\end{array}$ & & & \\
\hline & $\begin{array}{l}\text { DISC } \\
\text { SUST }\end{array}$ & $\begin{array}{c}\text { Disclosure } \\
\text { Sustentabilidade }\end{array}$ & & & \\
\hline \multirow{5}{*}{ Independentes } & CA & $\begin{array}{l}\text { Concentração } \\
\text { Acionária }\end{array}$ & $\begin{array}{l}\text { Porcentagem de } \\
\text { ações ordinárias } \\
\text { do maior acionista } \\
\text { controlador }\end{array}$ & \multirow{5}{*}{$\begin{array}{l}\text { Formulário de } \\
\text { Referência - } \\
\text { item 15.1/2 }\end{array}$} & $\begin{array}{l}\text { Dami et al. (2007); } \\
\text { Braga et. al. (2011) }\end{array}$ \\
\hline & FAM & Familiar & \multirow{4}{*}{$\begin{array}{l}\text { Variável dummy da } \\
\text { identidade acionária }\end{array}$} & & \multirow{4}{*}{ Carvalhal-da-Silva (2004) } \\
\hline & EST & Estatal & & & \\
\hline & ESTR & Estrangeiro & & & \\
\hline & INST & Institucional & & & \\
\hline \multirow[b]{2}{*}{ Controle } & ALAV & Alavancagem & Passivo Exigível/Ativo & \multirow{2}{*}{$\begin{array}{l}\text { Demonstrações } \\
\text { Financeiras } \\
\text { Padronizadas }\end{array}$} & $\begin{array}{l}\text { Sarlo (2009); Crisóstomo et al. } \\
\text { (2013); lyer e Lulseged (2013) }\end{array}$ \\
\hline & $\mathrm{ROA}$ & Return on Assets & Lucro Líquido/Ativo & & $\begin{array}{l}\text { Murcia (2009); Crisóstomo } \\
\text { et al. (2013); Muttakin e } \\
\text { Subramaniam (2015) }\end{array}$ \\
\hline
\end{tabular}

Fonte: elaborado pelos autores.

Neste sentido, desenvolveu-se um modelo de regressão para cada tipo de disclosure: econômico, social, ambiental e da sustentabilidade; conforme as equações apresentadas a seguir:

$$
\begin{aligned}
& \text { DISC_ECO }_{i}=\beta_{0}+\beta_{1} \mathrm{CA}_{\mathrm{i}}+\beta_{2} \mathrm{FAM}_{\mathrm{i}}+\beta_{3} \mathrm{EST}_{\mathrm{i}}+\beta_{4} \mathrm{ESTR}_{\mathrm{i}}+\beta_{5} \mathrm{ALAV}_{\mathrm{i}}+\beta_{6} \mathrm{ROA}_{\mathrm{i}} \\
& \text { DISC_SOC }_{\mathrm{i}}=\beta_{0}+\beta_{1} \mathrm{CA}_{\mathrm{i}}+\beta_{2} \mathrm{FAM}_{\mathrm{i}}+\beta_{3} \mathrm{EST}_{\mathrm{i}}+\beta_{4} \mathrm{ESTR}_{\mathrm{i}}+\beta_{5} \mathrm{ALAV}_{\mathrm{i}}+\beta_{6} \mathrm{ROA}_{\mathrm{i}} \\
& \text { DISC_AMB }_{\mathrm{i}}=\beta_{0}+\beta_{1} \mathrm{CA}_{\mathrm{i}}+\beta_{2} \mathrm{FAM}_{\mathrm{i}}+\beta_{3} \mathrm{EST}_{\mathrm{i}}+\beta_{4} \mathrm{ESTR}_{\mathrm{i}}+\beta_{5} \mathrm{ALAV}_{\mathrm{i}}+\beta_{6} \mathrm{ROA}_{\mathrm{i}} \\
& \text { DISC_SUST }_{\mathrm{i}}=\beta_{0}+\beta_{1} \mathrm{CA}_{\mathrm{i}}+\beta_{2} \mathrm{FAM}_{\mathrm{i}}+\beta_{3} \mathrm{EST}_{\mathrm{i}}+\beta_{4} \mathrm{ESTR}_{\mathrm{i}}+\beta_{5} \mathrm{ALAV}_{\mathrm{i}}+\beta_{6} \mathrm{ROA}_{\mathrm{i}}
\end{aligned}
$$

Para validação dos modelos, foram realizados os testes dos pressupostos das regressões (independência, normalidade e homocedasticidade dos resíduos e ausência de multicolinearidade das variáveis independentes).

O sistema estatístico utilizado para o tratamento dos dados foi o software Statistical Package for Social Sciences (SPSS). 


\section{Análise de Resultados}

\subsection{Caracterização das empresas}

O presente estudo estabeleceu como variáveis o controle acionário e a identidade do acionista controlador para verificar o relacionamento existente entre elas e a divulgação econômica e socioambiental das organizações. Deste modo, na medida em que o disclosure é abordado em suas três dimensões, tanto de modo individual quanto de modo integrado, a análise descritiva realizada buscou trazer um melhor detalhamento dos referidos níveis de disclosure quanto às duas características referentes à estrutura de propriedade em foco.

Assim, a partir da Tabela 2, tem-se a estatística descritiva referente ao nível de disclosure, por dimensão.

Tabela 2

Estatística descritiva dos níveis de disclosure das empresas no ano de 2012

\begin{tabular}{|c|c|c|c|c|c|c|c|}
\hline Disclosure & $\mathbf{N}$ & Mínimo & Máximo & Média & Mediana & $\begin{array}{l}\text { Desvio } \\
\text { padrão }\end{array}$ & $\begin{array}{l}\text { Coeficiente de } \\
\text { variação }\end{array}$ \\
\hline Econômico & 47 & $22,22 \%$ & $100 \%$ & $75,77 \%$ & $88,89 \%$ & $23,53 \%$ & $31,05 \%$ \\
\hline Social & 47 & $13,33 \%$ & $100 \%$ & $73,31 \%$ & $75,56 \%$ & $20,45 \%$ & $27,89 \%$ \\
\hline Ambiental & 47 & $11,67 \%$ & $100 \%$ & $68,62 \%$ & $71,67 \%$ & $22,17 \%$ & $32,31 \%$ \\
\hline Sustentabilidade & 47 & $19,05 \%$ & $100 \%$ & $71,90 \%$ & $72,62 \%$ & $19,74 \%$ & $27,45 \%$ \\
\hline
\end{tabular}

Fonte: dados da pesquisa.

A partir da análise dos dados, nota-se que foi atingida a divulgação máxima dos indicadores GRI em cada uma das três perspectivas de forma isolada, bem como das três em conjunto. Através dos valores mínimos, percebe-se, ainda, que nenhuma das 47 empresas da amostra deixou de divulgar totalmente todos os indicadores. Além disso, verifica-se que a média dos quatro níveis de disclosure ficou em torno de $70 \%$, sendo a mediana superior às médias de todos os tipos de evidenciação, indicando que metade das empresas apresentam divulgações superiores à média de cada perspectiva. Vale destacar que a evidenciação ambiental é a que apresenta tanto a menor média quanto a maior variabilidade dos dados, se comparada com os resultados verificados para os demais níveis de disclosure, fato este que sinaliza uma menor divulgação de itens nessa perspectiva.

Para a discussão das características do disclosure em relação ao controle acionário, foi realizada a divisão da amostra em três grupos, com base no percentual de ações detido pelo acionista controlador, segundo a classificação de Pedersen e Thomsen (1997). Assim, a Tabela 3 apresenta a estatística descritiva dos níveis de disclosure de acordo com a concentração acionária das empresas no ano de 2012. 
Tabela 3

Estatística descritiva dos níveis de disclosure em 2012, segregada de acordo com a concentração acionária das empresas

\begin{tabular}{|c|c|c|c|c|c|c|c|c|}
\hline Disclosure & Concentração & $\mathbf{N}$ & Mínimo & Máximo & Média & Mediana & $\begin{array}{l}\text { Desvio } \\
\text { padrão }\end{array}$ & $\begin{array}{l}\text { Coeficiente } \\
\text { de variação }\end{array}$ \\
\hline \multirow{3}{*}{ Econômico } & menos de $20 \%$ & 2 & $33,33 \%$ & $61,11 \%$ & $47,22 \%$ & $47,22 \%$ & $19,64 \%$ & $41,59 \%$ \\
\hline & entre $20 \%$ e $50 \%$ & 15 & $22,22 \%$ & $100,00 \%$ & $68,52 \%$ & $77,78 \%$ & $29,07 \%$ & $42,43 \%$ \\
\hline & mais de $50 \%$ & 30 & $44,44 \%$ & $100,00 \%$ & $81,30 \%$ & $88,89 \%$ & $18,48 \%$ & $22,73 \%$ \\
\hline \multirow{3}{*}{ Social } & menos de $20 \%$ & 2 & $55,56 \%$ & $62,22 \%$ & $58,89 \%$ & $58,89 \%$ & $4,71 \%$ & $8,00 \%$ \\
\hline & entre $20 \%$ e $50 \%$ & 15 & $13,33 \%$ & $100,00 \%$ & $68,89 \%$ & $62,22 \%$ & $27,32 \%$ & $39,65 \%$ \\
\hline & mais de $50 \%$ & 30 & $35,56 \%$ & $100,00 \%$ & $76,48 \%$ & $81,11 \%$ & $16,35 \%$ & $21,37 \%$ \\
\hline \multirow{3}{*}{ Ambiental } & menos de $20 \%$ & 2 & $56,67 \%$ & $63,33 \%$ & $60,00 \%$ & $60,00 \%$ & $4,71 \%$ & $7,86 \%$ \\
\hline & entre $20 \%$ e $50 \%$ & 15 & $11,67 \%$ & $100,00 \%$ & $67,78 \%$ & $73,33 \%$ & $29,94 \%$ & $44,18 \%$ \\
\hline & mais de $50 \%$ & 30 & $30,00 \%$ & $100,00 \%$ & $69,61 \%$ & $72,50 \%$ & $18,42 \%$ & $26,47 \%$ \\
\hline \multirow{3}{*}{ Sustentabilidade } & menos de $20 \%$ & 2 & $57,14 \%$ & $58,93 \%$ & $58,04 \%$ & $58,04 \%$ & $1,26 \%$ & $2,18 \%$ \\
\hline & entre $20 \%$ e $50 \%$ & 15 & $19,05 \%$ & $100,00 \%$ & $68,45 \%$ & $65,48 \%$ & $27,41 \%$ & $40,04 \%$ \\
\hline & mais de $50 \%$ & 30 & $40,48 \%$ & $100,00 \%$ & $74,54 \%$ & $75,60 \%$ & $15,11 \%$ & $20,27 \%$ \\
\hline
\end{tabular}

Fonte: dados da pesquisa.

Com base na Tabela 3, nota-se que poucas são as empresas que apresentam acionista controlador com menos de $20 \%$ do controle da empresa (2), ao passo que mais da metade da amostra (30) possui alta concentração acionária, situando-se acima de $50 \%$ do total das ações ordinárias. Esse resultado corrobora Brandão (2004), que também identificou a alta concentração acionária como característica do mercado de capitais brasileiro.

As empresas que possuíam acionistas detentores de menos de $20 \%$ do controle foram as que apresentaram os menores níveis médios de evidenciação de informações. Em relação às empresas que possuíam acionistas controladores de $20 \%$ a $50 \%$ das ações ordinárias, percebe-se que as médias dos níveis de disclosure apresentam-se homogêneas, visto que a divulgação abrange em torno de $68 \%$ dos indicadores de cada uma das perspectivas. No entanto, tais empresas apresentam a maior variabilidade em todos os tipos de disclosure.

Quanto às empresas que possuíam acionistas detentores de mais de $50 \%$ do controle, os resultados sinalizam um nível de evidenciação de informações mais elevado, tendo em vista que as médias de disclosure das perspectivas econômica (81,30\%), social (76,48\%), ambiental (69,61\%) e de sustentabilidade $(74,54 \%)$ foram superiores nesse grupo de empresas. Adicionalmente, é necessário ressaltar que os dados apresentam uma baixa variabilidade, corroborando a indicação de que, na amostra em análise, empresas de maior controle acionário divulgam mais informações acerca da sustentabilidade empresarial.

Além disso, analisou-se o disclosure em relação à identidade do acionista controlador, dos resultados estão expressos na Tabela 4 . 
Tabela 4

Estatística descritiva dos níveis de disclosure em 2012, segregada de acordo com a identidade do acionista controlador

\begin{tabular}{|c|c|c|c|c|c|c|c|c|}
\hline Disclosure & Identidade & $\mathbf{N}$ & Mínimo & Máximo & Média & Mediana & $\begin{array}{l}\text { Desvio } \\
\text { padrão }\end{array}$ & $\begin{array}{l}\text { Coeficiente } \\
\text { de variação }\end{array}$ \\
\hline \multirow{4}{*}{ Econômico } & Familiar & 14 & $22,22 \%$ & $88,89 \%$ & $69,84 \%$ & $77,78 \%$ & $21,98 \%$ & $31,47 \%$ \\
\hline & Estatal & 8 & $44,44 \%$ & $100,00 \%$ & $87,50 \%$ & $94,44 \%$ & $19,19 \%$ & $21,93 \%$ \\
\hline & Estrangeira & 15 & $27,78 \%$ & $100,00 \%$ & $75,19 \%$ & $88,89 \%$ & $23,84 \%$ & $31,70 \%$ \\
\hline & Institucional & 10 & $22,22 \%$ & $100,00 \%$ & $75,56 \%$ & $88,89 \%$ & $27,99 \%$ & $37,04 \%$ \\
\hline \multirow{4}{*}{ Social } & Familiar & 14 & $34,44 \%$ & $97,78 \%$ & $66,11 \%$ & $62,22 \%$ & $20,55 \%$ & $31,08 \%$ \\
\hline & Estatal & 8 & $67,78 \%$ & $100,00 \%$ & $84,03 \%$ & $82,22 \%$ & $11,88 \%$ & $14,14 \%$ \\
\hline & Estrangeira & 15 & $42,22 \%$ & $100,00 \%$ & $74,22 \%$ & $80,00 \%$ & $18,71 \%$ & $25,20 \%$ \\
\hline & Institucional & 10 & $13,33 \%$ & $100,00 \%$ & $73,44 \%$ & $78,89 \%$ & $26,24 \%$ & $35,73 \%$ \\
\hline \multirow{4}{*}{ Ambiental } & Familiar & 14 & $11,67 \%$ & $90,00 \%$ & $62,02 \%$ & $65,00 \%$ & $22,56 \%$ & $36,38 \%$ \\
\hline & Estatal & 8 & $40,00 \%$ & $100,00 \%$ & $71,04 \%$ & $73,33 \%$ & $22,13 \%$ & $31,15 \%$ \\
\hline & Estrangeira & 15 & $30,00 \%$ & $100,00 \%$ & $72,11 \%$ & $73,33 \%$ & $19,50 \%$ & $27,04 \%$ \\
\hline & Institucional & 10 & $26,67 \%$ & $100,00 \%$ & $70,67 \%$ & $70,00 \%$ & $26,58 \%$ & $37,61 \%$ \\
\hline \multirow{4}{*}{ Sustentabilidade } & Familiar & 14 & $25,00 \%$ & $93,45 \%$ & $65,05 \%$ & $63,69 \%$ & $19,65 \%$ & $30,21 \%$ \\
\hline & Estatal & 8 & $63,10 \%$ & $100,00 \%$ & $79,76 \%$ & $76,19 \%$ & $13,16 \%$ & $16,50 \%$ \\
\hline & Estrangeira & 15 & $40,48 \%$ & $99,40 \%$ & $73,57 \%$ & $75,00 \%$ & $17,93 \%$ & $24,37 \%$ \\
\hline & Institucional & 10 & $19,05 \%$ & $100,00 \%$ & $72,68 \%$ & $76,79 \%$ & $25,78 \%$ & $35,47 \%$ \\
\hline
\end{tabular}

Fonte: dados da pesquisa.

A partir da Tabela 4, verifica-se que, de uma amostra de 47 empresas, a identidade estatal mostrou-se menos representativa, com um total de 8 empresas. Além disso, percebeu-se que, para o contexto da amostra em análise, as empresas de controle familiar (14) apresentaram-se em menor número do que as de controle estrangeiro (15). No entanto, conforme indicado por Braga et. al. (2011) e Sarlo (2009), as empresas de capital aberto no Brasil são, predominantemente, controladas por famílias. Assim, uma explicação para a participação mais expressiva de empresas de controle estrangeiro reside na maior atenção dada por tais acionistas às questões relativas à sustentabilidade, conforme indicado por Oh et al. (2011), o que pode, portanto, impactar na própria divulgação de informações acerca da sustentabilidade empresarial.

Por meio do cruzamento das informações acerca da identidade acionária e dos níveis de disclosure, percebe-se que nenhuma empresa de controle acionário familiar apresentou divulgação completa em qualquer dos tipos de disclosure em análise. Em comparação com as demais, tais empresas foram as que apresentaram os menores níveis médios de disclosure, os quais ficaram abaixo de $70 \%$, sendo o menor deles o disclosure de informações ambientais (62,02\%).

Ao confrontar a média de divulgação ambiental das empresas familiares $(62,02 \%)$ com a média geral dessa perspectiva (68,62\%), observada na Tabela 2, há uma sinalização de que empresas de controle familiar foram as principais responsáveis pela diminuição da média geral do disclosure ambiental. Isso pode ser também verificado por meio da análise do índice de disclosure ambiental das demais identidades acionárias, posto que, enquanto as empresas familiares apresentaram média de divulgação de $62,02 \%$, as empresas das demais identidades - estatal, estrangeira e institucional - apresentaram evidenciação de, aproximadamente, $71 \%$ dos indicadores ambientais.

As organizações de controle estatal apresentaram maior média tanto no nível de disclosure econômico e social quanto no nível de disclosure de informações acerca da sustentabilidade empresarial (79,76\%). Em relação a este último, verificou-se uma menor variabilidade dos dados, visto que seu desvio padrão e coeficiente de variação foram, respectivamente, 13,16\% e 16,5\%. Esse elevado nível de evidenciação de 
informações também é sinalizado pelos valores máximos e mínimos de todos os tipos de disclosure (econômico, social, ambiental e de sustentabilidade), que se apresentaram mais favoráveis quando comparados aos das demais empresas.

Quanto às empresas de controle estrangeiro, nota-se uma homogeneidade nos níveis de disclosure, visto que encontram-se em torno de $72 \%$ e $75 \%$. Além disso, percebe-se que tais tipos de empresas foram as que mais divulgaram informações de cunho ambiental $(72,11 \%)$. Por fim, nota-se que as empresas de controle acionário institucional são as que apresentam a maior variabilidade dos dados, comparativamente às demais empresas de identidades diversas.

\subsection{Relação entre estrutura de propriedade e disclosure econômico e socioambiental}

Realizada a análise descritiva, que permitiu o conhecimento da amostra do estudo, passou-se à análise da Regressão Linear Múltipla, buscando investigar a relação existente entre a estrutura de propriedade e o disclosure econômico e socioambiental.

Conforme apontado na metodologia do presente estudo, foram realizados os testes dos pressupostos das regressões (ausência de independência dos resíduos, multicolinearidade, normalidade dos resíduos e homocedasticidade), verificando-se o atendimento de tais pressupostos. Desse modo, a Tabela 5 apresenta os resultados dos quatro modelos de regressão empregados na pesquisa.

Tabela 5

Resultados da Regressão Linear Múltipla

\begin{tabular}{|c|c|c|c|c|}
\hline \multirow{2}{*}{ Variável } & \multicolumn{4}{|c|}{ Disclosure } \\
\hline & Econômico & Social & Ambiental & Sustentabilidade \\
\hline Intercepto & 0,958 & 0,674 & 0,806 & 0,751 \\
\hline Concentração & 0,207 & 0,149 & 0,047 & 0,119 \\
\hline Familiar & $-0,053$ & $-0,064$ & $-0,082$ & $-0,069$ \\
\hline Estatal & 0,042 & 0,087 & $-0,020$ & 0,044 \\
\hline Estrangeiro & $-0,047$ & 0,002 & 0,010 & 0,000 \\
\hline ROA & $-0,448$ & $-0,315$ & $-0,267$ & $-0,312$ \\
\hline Alavancagem & $-0,436\left(^{*}\right)$ & $-0,005$ & $-0,174$ & $-0,111$ \\
\hline $\mathrm{N}$ & 47 & 47 & 47 & 47 \\
\hline $\mathrm{R}^{2}$ & 0,186 & 0,132 & 0,058 & 0,107 \\
\hline $\mathrm{R}^{2}$ ajustado & 0,064 & 0,002 & $-0,083$ & $-0,027$ \\
\hline Teste F & 1,526 & 1,012 & 0,413 & 0,799 \\
\hline p-valor & 0,195 & 0,431 & 0,866 & 0,576 \\
\hline
\end{tabular}

(*) Significante ao nível de $10 \%$

Fonte: dados da pesquisa.

A partir da Tabela 5, verifica-se que os modelos não apresentam significância estatística, indicando que nenhuma das variáveis independentes, isoladamente, exerce influência sobre o disclosure referente às perspectivas econômica, social, ambiental ou das três em conjunto (sustentabilidade). Assim, a partir dos resultados encontrados, é possível inferir que nem a concentração, nem a identidade do acionista exercem influência sobre o disclosure das empresas pertencentes à amostra. 
Diante disso, apesar de se ter a divulgação de informações socioambientais como importante para a legitimação da atuação empresarial perante a sociedade (Cardoso et al., 2012; Sampaio et al., 2012; Costa et al., 2013; Muttakin \& Subramaniam, 2015), os resultados do presente estudo sinalizaram que a estrutura de propriedade não é fator influenciador do disclosure socioambiental, podendo indicar que os acionistas, identificados a partir da estrutura de propriedade e controle da empresa, não concebem a divulgação de tais informações como aspecto legitimador.

Dessa forma, devido à ausência de significância dos modelos de regressão testados, verifica-se que as hipóteses propostas pelo presente estudo, de que havia relação tanto entre o controle acionário e o disclosure econômico e socioambiental $\left(\mathrm{H}_{1}\right)$ quanto entre a identidade do acionista controlador e o nível de disclosure econômico e socioambiental $\left(\mathrm{H}_{2}\right)$, não podem ser aceitas.

Tais resultados divergem dos achados de Ghazali (2007) e Saleh et al. (2010), que verificaram relação entre o disclosure de informações acerca da sustentabilidade empresarial e a estrutura de propriedade. Por outro lado, corroboram os resultados do trabalho de Iyer e Lulseged (2013), que não encontraram diferença estatisticamente significante entre as empresas familiares e não familiares da amostra quanto à divulgação de informações nos relatórios de sustentabilidade.

Além disso, nota-se que a literatura diverge não apenas no que diz respeito à relação entre o disclosure e a estrutura de propriedade das organizações, tal divergência também é verificada no relacionamento entre as ações tomadas no âmbito da sustentabilidade empresarial e a estrutura de propriedade, tanto no que diz respeito ao controle (Dam \& Scholtens, 2013; Crisóstomo et al., 2013) quanto à identidade acionária (Oh et al., 2011; Block \& Wagner, 2014).

\section{Considerações Finais}

A pesquisa teve como objetivo geral investigar a relação entre a estrutura de propriedade e o disclosure voluntário econômico e socioambiental nas maiores empresas brasileiras. Para tanto, além de dados financeiros, foram coletados dados acerca da identidade e da concentração acionária, bem como da divulgação de informações econômicas e socioambientais de 47 das 100 maiores empresas de capital aberto da BM\&FBOVESPA referentes ao exercício social de 2012.

A análise descritiva dos níveis de disclosure indicou que, apesar de não existir grande variabilidade entre as perspectivas analisadas (econômico, social, ambiental e de sustentabilidade), a evidenciação ambiental demonstrou a menor média de divulgação, além de apresentar a maior variabilidade de dados. Quanto à identidade do acionista controlador e à representatividade na amostra, as empresas estatais e as de controle estrangeiro mostraram menor e maior representatividade, respectivamente. Relacionando a identidade do acionista controlador com os níveis de disclosure, as empresas familiares apresentaram menor média de divulgação, principalmente nas informações ambientais. Já as organizações de controle estatal destacaram-se com maior média em três dos quatro níveis de disclosure, sendo eles: o econômico, o social e o de sustentabilidade. Além disso, as empresas de controle estrangeiro foram as que mais divulgaram informações ambientais.

Os resultados do teste estatístico não demonstraram relação significante entre a estrutura de propriedade e o disclosure econômico e socioambiental. Infere-se, portanto, que nem a concentração nem a identidade do acionista exercem influência sobre o disclosure das empresas pertencentes à amostra, ou seja, tal aspecto legitimador - o disclosure de informações relativas à sustentabilidade empresarial - não é influenciado pela estrutura de propriedade da empresa. Portanto, verifica-se a não aceitação das hipóteses $\mathrm{H}_{1} \mathrm{e} \mathrm{H}_{2}$.

Como contribuição, o presente estudo colabora para o desenvolvimento e crescimento, em âmbito nacional, da temática sobre estrutura de propriedade e disclosure econômico e socioambiental. Além disso, busca-se contribuir tanto em aspectos teóricos quanto empíricos, tendo em vista que essa temática encontra-se em processo de desenvolvimento, apresentando divergências consideráveis quanto aos resultados encontrados em pesquisas internacionais. 
Como limitações da pesquisa, ressalta-se a análise de apenas um ano, impossibilitando uma comparação mais detalhada, além do número reduzido de empresas que compuseram a amostra, restrita às maiores empresas de capital aberto do Brasil. A coleta de dados também pode ser tida como uma limitação, posto que não foi considerada a qualidade das informações divulgadas nos relatórios de sustentabilidade, além de o nível de divulgação das informações ser mensurado por meio dos indicadores declarados pelas empresas. Sugerem-se para pesquisas futuras a realização de uma análise longitudinal e a inclusão de mais variáveis no modelo estatístico ou até mesmo a utilização de outras técnicas para a análise de dados. Além disso, torna-se necessário verificar a existência de tal relação em organizações tanto do Brasil quanto de outros países, visto que a literatura nesta temática apresenta resultados diversos.

\section{Referências}

Amran, A., \& Ooi, S. K. (2014). Sustainability reporting: meeting stakeholder demands. Strategic Direction, 30(7), pp. 38-41. doi: 10.1108/SD-03-2014-0035

Berle, A., \& Means, G. (1932). The modern corporation and private property. New York: Macmillan.

Beuren, I. M., \& Söthe, A. (2009). A teoria da legitimidade e o custo político nas evidenciações contábeis dos governos estaduais da região sudeste do Brasil. Revista de Contabilidade e Organizações - RCO, 3(5), pp. 98-120. doi: 10.11606/rco.v3i5.34734

Block, J. H., \& Wagner, M. (2014). The effect of family ownership on different dimensions of corporate social responsibility: evidence from large US firms. Business Strategy and the Environment. 23(7), pp. 475-496. doi: 10.1002/bse.1798

Borba, P. R. F. (2006, setembro). Relação entre desempenho social corporativo e desempenho financeiro de empresas no Brasil. Anais do Encontro da Associação Nacional de Pós-Graduação e Pesquisa em Administração - EnANPAD, Salvador, BA, Brasil, 30.

Borges, A. P., Rosa, F. S., \& Ensslin, S. R. (2010). Evidenciação voluntária das práticas ambientais: um estudo nas grandes empresas brasileiras de papel e celulose. Produção, 20(3), pp. 404-417. doi: 10.1590/ S0103-65132010005000034

Braga, C., Santos, A., Silva, P. P., \& Nunes, R. V. (2011, setembro). A influência da origem do controle acionário no nível de disclosure ambiental no setor de energia elétrica no Brasil. Anais do Encontro da Associação Nacional de Pós-Graduação e Pesquisa em Administração - EnANPAD, Rio de Janeiro, RJ, Brasil, 35.

Braga, J. P., Oliveira, J. R. S., \& Salotti, B. M. (2009). Determinantes do nível de divulgação ambiental nas demonstrações contábeis de empresas brasileiras. Revista de Contabilidade da UFBA, 3(3), pp. 81-95.

Brandão, M. M. (2004). Governança corporativa e a influência dos acionistas minoritários no sistema de decisões estratégicas. Dissertação de mestrado profissional, Pontifícia Universidade Católica de Minas Gerais, Belo Horizonte, MG, Brasil. Recuperado de http://www.biblioteca.pucminas.br/teses/ Administracao_BrandaoMM_1.pdf

Cardoso, V. I. C., De Luca, M. M. M., \& Almeida, T. A. (2012, novembro). Práticas de disclosure econômico e socioambiental nas maiores empresas do Brasil. Anais do Encontro Nacional sobre Gestão Empresarial e Meio Ambiente - ENGEMA, São Paulo, SP, Brasil, 14.

Carvalhal-da-Silva, A. L. (2004). Governança corporativa, valor, alavancagem e política de dividendos das empresas brasileiras. Revista de Administração USP - RAUSP, 39(4), pp. 348-361.

Collis, J., \& Hussey, R. (2005). Pesquisa em administração: um guia prático para alunos de graduação e pós-graduação ( $2^{a}$ ed.). Porto Alegre: Bookman. 
Costa, M. I.; Torres, L. S.; Vasconcelos, A. C., \& De Luca, M. M. M. (2013). Classificação do conteúdo dos relatórios de sustentabilidade de empresas premiadas por suas práticas de responsabilidade socioambiental. Revista de Educação e Pesquisa em Contabilidade - REPeC, 7(2), pp. 147-166. doi: $10.17524 /$ repec.v7i2.629

Crisóstomo, V. L.; Freire, F. S., \& Parente, P. H. N. (2013, junho). Ownership concentration favors corporate social responsibility of Brazilian firm. Anais do Congresso da Associação Nacional de Programas de Pós-Graduação em Ciências Contábeis - ANPCONT, Fortaleza, CE, Brasil, 7.

Cunha, J. V. A., \& Coelho, A. C. (2007). Regressão linear múltipla. In L. J. Corrar, E. Paulo, \& J. M. Dias Filho (Coords.). Análise multivariada: para os cursos de administração, ciências contábeis e economia, pp. 131-231. São Paulo: Atlas.

Dam, L., \& Scholtens, B. (2012). Does ownership type matter for corporate social responsibility? Corporate Governance: An International Review, 20(3), pp. 233-252. doi: 10.1111/j.1467-8683.2011.00907.x

Dam, L., \& Scholtens, B. (2013). Ownership concentration and CSR policy of European multinational enterprises. Journal of Business Ethics, 118(1), pp. 117-126. doi: 10.1007/s10551-012-1574-1

Dami, A. B. T., Rogers, P. \& Ribeiro, K. C. S. (2007) Estrutura de propriedade no Brasil: evidências empíricas no grau de concentração acionária. Revista Contemporânea de Economia e Gestão - Contextus, 5(2), pp. 21-30.

De Luca, M. M. M., Assunção, R. R., \& Costa, J. A. (2013, dezembro). Fatores determinantes do disclosure voluntário de empresas do Brasil e de países desenvolvidos, sob o enfoque da sustentabilidade. Anais do Encontro Nacional sobre Gestão Empresarial e Meio Ambiente - ENGEMA, São Paulo, SP, Brasil, 15.

Deegan, C. (2005). Legitimacy theory. In Z. Hoque (Coord.). Methodological issues in accounting research: theories and methods, pp. 161- 179. Londres: Spiramus.

Dias, J. M., Filho (2007, setembro). Políticas de evidenciação contábil: um estudo do poder preditivo e explicativo da teoria da legitimidade. Anais do Encontro da Associação Nacional de Pós-Graduação e Pesquisa em Administração - EnANPAD, Rio de Janeiro, RJ, Brasil, 31.

Díez, J. L. G., Gago, R. F., \& García, L. C. (2011). Propriedad y control en la puesta en práctica de la RSC. Cuardenos de Economía y Dirección de la Empresa, 15(1), pp. 1-11. doi: 10.1016/j.cede.2011.06.002

Dyer, W. G., Jr., \& Whetten, D. A. (2006). Family firms and Social Responsibility: preliminary evidence from the S\&P 500. Entrepreneurship Theory and Practice, 30(6), pp. 785-802. doi: 10.1111/j.1540$-6520.2006 .00151 . x$

Fonseca, F. A. P. B., Almeida, K. K. N., \& França, R. D. (2012). Evidenciação de informações ambientais em empresas do segmento de utilidade pública listadas na BM\&FBovespa: um estudo sobre a evolução na divulgação dessas informações. Revista de Administração, Contabilidade e Sustentabilidade - REUNIR, 2(3), pp. 51-68. doi: 10.18696/reunir.v2i3.63

Gallo, P. J., \& Christensen, L. J. (2011). Firm size matters: an empirical investigation of organizational size and ownership on sustainability-related behaviors. Business Society, 50(2), pp. 315-349. doi: $10.1177 / 0007650311398784$

García, L. C., Navarro, M. S., \& Ansón, S. G. (2014). Propiedad familiar, control y efecto generación y RSC. Revista de Empresa Familiar, 4(1), pp. 9-20.

Garcia, S., Cintra, Y. C., Ribeiro, M. S., \& Dibbern, B. R. S. (2015). Qualidade da divulgação socioambiental: um estudo sobre a acurácia das informações contábeis nos relatórios de sustentabilidade. Revista Contemporânea de Contabilidade - RCC, 12(25), pp. 67-94. doi: 10.5007/2175-8069.2015v12n25p95

Ghazali, N. A. M. (2007). Ownership structure and corporate social responsibility disclosure: some Malaysian evidence. Corporate Governance, 7(3), pp. 251-266. doi: 10.1108/14720700710756535 
Gillan, S. L., \& Starks, L. T. (2003, agosto). Corporate governance, corporate ownership, and the role of institutional investors: a global perspective [Working Paper Series]. John L. Weinberg Center for Corporate Governance, University of Delaware. Recuperado em 05 de maio, 2014, de http://papers. ssrn.com/sol3/papers.cfm?abstract_id $=439500$

Gondrige, E. O., Espejo, M. M. S. B., Clemente, A., \& Silva, W. V. (2011, setembro). Fatores explicativos do disclosure voluntário das empresas brasileiras de capital aberto sob a perspectiva da estrutura de governança corporativa e de propriedade. Anais do Encontro da Associação Nacional de Pós-Graduação e Pesquisa em Administração - EnANPAD, Rio de Janeiro, RJ, Brasil, 35.

Hair, J. F., Jr., Babin, B., Money, A. H., \& Samouel, P. (2005). Fundamentos de métodos de pesquisa em administração. Porto Alegre: Bookman. Professor não encontrei no texto

Iyer, V., \& Lulseged, A. (2013). Does family status impact US firms' sustainability reporting? Sustainability Accounting, Management and Policy Journal, 4(2), pp. 163-189. doi: 10.1108/SAMPJ-Nov-2011-0032

Javid, A. Y., \& Iqbal, R. (2008). Ownership concentration, corporate governance and firm performance: evidence from Pakistan. The Pakistan Development Review, 47(4), pp. 643-659.

Lima, L. S. (2013). Governança corporativa, valor e desempenho de empresas com participação acionária de fundos de pensão no Brasil. Dissertação de mestrado, Pontifícia Universidade Católica do Rio de Janeiro, Rio de Janeiro, RJ, Brasil.

Martini, L. C., Jr., Silva, E. R., \& Mattos, U. A. O. (2014). Análise da transparência corporativa por meio dos relatórios de sustentabilidade com base na Global Reporting Initiative de empresas do setor brasileiro de energia elétrica. Sistemas \& Gestão, 9(1), pp. 34-46. doi: 10.7177/sg.2014.v9.n1.a4 professor não encontrei no texto

Murcia, F. D. (2009). Fatores determinantes do nível de disclosure voluntário de companhias abertas no Brasil. 2009. 181 f. Tese de doutorado, Universidade de São Paulo, São Paulo, SP, Brasil.

Muttakin, M. B., \& Subramaniam, N. (2015). Firm ownership and board characteristics: do they matter for corporate social responsibility disclosure of Indian companies? Sustainability Accounting, Management and Policy Journal, 6(2), pp. 138-165. doi: 10.1108/SAMPJ-10-2013-0042

Oh, W. Y., Chang, Y. K., \& Martynov, A. (2011). The effect of ownership structure on corporate social responsibility: empirical evidence from Korea. Journal of Business Ethics, 104(2), pp. 283-297, 2011. doi: 10.1007/s10551-011-0912-Z

Okimura, R. T., Silveira, A. D. M., \& Rocha, K. C. (2007). Estrutura de propriedade e desempenho corporativo no Brasil. Revista de Administração Contemporânea - Eletrônica, 1(1), pp. 119-135.

Pedersen, T., \& Thomsen, S. (1997). European patterns of corporate ownership: a twelve-country study. Journal of International Business Studies, 28(4), pp. 759-778. doi: 10.1057/palgrave.jibs.8490118

Ribeiro, A. M.; Van Bellen; H. M.; Carvalho, L. N. G. (2011). Regulamentar faz diferença? O caso da evidenciação ambiental. Revista Contabilidade \& Finanças, 22(56), pp. 137-154. doi: 10.1590/S151970772011000200002

Roque, V., \& Cortez, M. C. (2006). A divulgação de informação ambiental e a performance financeira das empresas cotadas em Portugal. Tékhne - Revista de Estudos Politécnicos, 3(5/6), pp. 119-143.

Saleh, M., Zulkifli, N., \& Muhamad, R. (2010). Corporate social responsibility disclosure and its relation on institutional ownership: evidence from public listed companies in Malaysia. Managerial Auditing Journal, 25(6), pp. 591-613. doi: 10.1108/02686901011054881

Sampaio, M. S., Gomes, S. M. S., Bruni, A. L., \& Dias, J. M., Filho (2012). Evidenciação de informações socioambientais e isomorfismo: um estudo com mineradoras brasileiras. Revista Universo Contábil, 8(1), pp. 105-122. doi: 10.4270/ruc.2012107 
Sarlo, A., Neto (2009). Relação entre a estrutura de propriedade e a informatividade dos lucros contábeis no mercado brasileiro. Tese de doutorado, Universidade de São Paulo, São Paulo, SP, Brasil.

Silva, F. L., Chan, B. L., Furuta, F., \& Martins, G. A. (2007, setembro). Influências do controle acionário no disclosure de informações contábeis. Anais do Encontro da Associação Nacional de Pós-Graduação e Pesquisa em Administração - EnANPAD, Rio de Janeiro, RJ, Brasil, 31.

Sonza, I. B. (2012). Eficiência em estruturas de propriedade concentradas e compensação de executivos: novas evidências para o Brasil. Tese de doutorado, Universidade Federal do Rio Grande do Sul, Porto Alegre, RS, Brasil.

Wahab, E. A. A. W., How, J., \& Verhoeven, P. (2008). Corporate governance and institutional investors: evidence from Malaysia. Asian Academy of Management Journal of Accounting and Finance, 4(2), pp. 67-90. 